\title{
Bağrıbütün Kavununda Polimorfik Olan Bazı SSR Markörlerinin Belirlenmesi
}

\author{
Determination of Some Polymorphic SSR Markers in Bagributun Melon
}

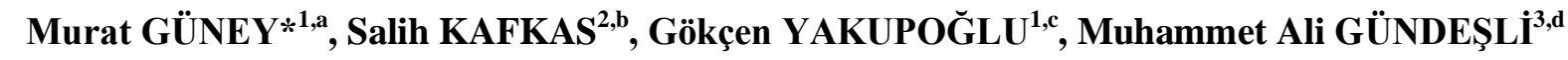 \\ ${ }^{l}$ Yozgat Bozok Üniversitesi, Ziraat Fakültesi, Bahçe Bitkileri Bölümü, Yozgat \\ ${ }^{2}$ Çukurova Üniversitesi, Ziraat Fakültesi, Bahçe Bitkileri Bölümü, Adana \\ ${ }^{3}$ Doğu Akdeniz Geçit Kuşağı Tarımsal Araştırma Enstitüsü, Kahramanmaraş
}

• Geliş tarihi / Received: 04.10.2019 • Düzeltilerek geliş tarihi / Received in revised form: $14.02 .2020 \quad$ • Kabul tarihi / Accepted: 05.03 .2020

\section{$\ddot{O} \mathbf{z}$}

Bitki genetik kaynaklarının elden çıkması çok kolay ancak geri kazanımları neredeyse imkânsız olmaktadır. Genetik materyallerin toplanması ve muhafaza altına alınması gelecekte yapılacak olan sslah programları için büyük önem arz etmektedir. Moleküler markörler kullanılarak, genotiplerin seleksiyonu, çoğaltılması, karakterizasyonu ve muhafazası mümkündür. DNA markör sistemleri farklı ekolojilerdeki genetik materyallerin karakterize edilmesini sağlamaktadır. Bu çalışmanın amacı, Yozgat'ın Aydıncık ilçesinde yetiştiriciliği yapılan eşsiz tat ve aromaya sahip Bağrıbütün kavununun SSR (Basit Dizi Tekrarları) moleküler markör tekniği ile DNA parmak izi çıkarılarak coğrafi işaretlemeye katkı sağlamaktır. 4 adet yerel Bağrıütün kavunu genotipinin 24 adet polimorfik SSR primeri ile genetik karakterizasyonu ortaya konulmuştur. DNA parmak izinin çıkarılmasında kullanılan polimorfik SSR primerlerinden CMSSR12254, CMSSR10506, CMSSR07989 ve CMSSR08902 primerleri yüksek oranda polimorfizm göstermiștir. Bu SSR primleri ile kavun genetik kaynaklarının genetik ilişklileri daha kısa sürede ve daha güvenilir sonuçlarla belirlenebilecektir.

Anahtar kelimeler: Cucumis melo L., DNA Parmak İzi, Kavun, SSR

\begin{abstract}
Plant genetic resources are easy to dispose of, but their recovery is almost impossible. The collection and preservation of genetic materials are of great importance for future breeding programs. The selection, amplification, characterization, and maintenance of genotypes are possible using molecular markers. DNA marker systems are used to characterize genetic materials of different ecologies. The aim of this study is to contribute to the geographic marking region-specific Bagributun melon with unique taste and aroma which is cultivated intensively in Aydincik district by extracting DNA fingerprints using SSR (Simple Sequence Repeats) molecular marker technique. Genetic characterization of 4 local melon genotypes was determined using 24 polymorphic SSR primers. Among all 4 primers (CMSSR12254, CMSSR10506, CMSSR07989, and CMSSR0890) showed high polymorphism and were used for DNA fingerprinting. Using these SSR primers, genetic relations of melon genetic resources can be determined in a shorter time and with more reliable results.
\end{abstract}

Keywords: Cucumis melo L., DNA Fingerprint, Melon, SSR

\footnotetext{
*a Murat GÜNEY; murat.guney@yobu.edu.tr, Tel: (0354) 242 10 94, orcid.org/0000-0003-2882-8347

${ }^{\mathrm{b}}$ orcid.org/0000-0002-9037-4764 $\quad{ }^{\mathrm{c}}$ orcid.org/0000-0003-4921-0925 $\quad{ }^{\mathrm{d}}$ orcid.org//0000-0002-7068-8248
} 


\section{Giriş}

Kavun (Cucumis melo L.); karpuz, hıyar, süs kabağ1, su kabakları, bal kabağı gibi birçok ticari bitkinin içinde olduğu, Cucurbitaceae familyasının bir üyesidir. Farklı coğrafik orijinlerden tanımlanmış yabani ve kültüre alınan birçok kavun tipi vardır (Pitrat vd., 2000). Ülkemiz coğrafi yapısı ve ekolojik koşulları nedeniyle kavun yetiştiriciliğinde önemli bir yere sahiptir. Pek çok bitkinin gen merkezidir ve gen kaynaklarına sahiptir (Günay, 1993). Bu açıdan ülkemizin sürdürülebilir tarımı için mevcut genetik kaynaklarımızın yok olmadan muhafaza altına alınması gerekmektedir (Özgen vd., 2000; İnal, 2002). Çiftçilerin süregelen yetiştiricilik dönemleri boyunca beğenileri doğrultusunda seleksiyonla 1slah ettikleri ve bulundukları yöreye uyum sağlamış olan bir kültür bitkisine ait genotipler, yerel çeşit ya da köy çeşidi olarak adlandırılır (Tan, 2009). Yerel çeşitler; çoğunlukla kalite özellikleri yüksek, bölgeye adapte olmuş bireylerin seçilmesi ve birbirini izleyen nesillerde seleksiyona devam edilip, seçilen bireylerle yetiştiriciliğin sürdürülmesiyle ve doğal seleksiyonun etkisi ile ortaya çıkmıştır (Kaşka, 2019). Yerel çeşitlerin, yetiştirildikleri farklı ekolojilere adaptasyon yetenekleri yüksektir. $\mathrm{Bu}$ nedenle, ait oldukları türün evrim potansiyelinin bask1 faktörlerine karşı korunması sağlanmalıdır (Kutlu, 2017). Yerel çeşitlerin değerlendirilmesi, doğrudan bu çeşitlerin yetiştiriciliğinin ve tüketiminin teşvik edilmesi ya da dolaylı olarak bu çeşitlerin yeni çeşitler geliştirmek üzere yürütülen ıslah çalışmalarında kullanılması yoluyla gerçekleştirilebilir (Özçağıran, 2004). Yerel çeşitler içerdikleri zengin genetik çeşitlilik ile son yıllarda hizla ilerleyen biyoteknolojik imkânlar kullanılarak üstün nitelikli çeşitlerin geliştirilmesi için gerekli ham madde niteliğindedir (Eser vd., 2005). Ticari çeşitlerin yaygın kullanımı yerel çeşitlerin daha az tercih edilmelerine ve zamanla yok olmalarına neden olmaktadır. Yerel çeşitlere gereken önemin verilmesi ve en azından kayıt altına alınmaları gerekmektedir. Bu tür çalışmalar yapılmadığında üreticilerin üretimden vazgeçmeleri halinde genetik kaynaklar zamanla yok olacaktır (Kaşka, 2019). $\mathrm{Bu}$ sebeple genetik kaynakların tanımlanması, DNA parmak izlerinin çıkartılması ve muhafaza altına alınmaları ıslah çalışmaları için önem arz etmektedir (Çalışkan, 2005; Gülşen ve Mutlu, 2005; Şensoy vd., 2007). Moleküler markörler bitki sistematiğinde, bitki sslahında ve genetik kaynaklarının değerlendirilmesinde etkin olarak kullanılmaktadır (Kafkas vd., 2008). RAPD (Random Amplified Polymorphic DNA-Rastgele
Çoğaltılmış Polimorfik DNA), ISSR (Inter Simple Sequence Repeat-Basit Tekrarlı Diziler Aras1 Polimorfizm), SSR (Simple Sequence RepeatBasit Dizi Tekrarları), SNP (Single Nucleotide Polymorphism-Tek Nükleotid Polimorfizmi) gibi DNA esaslı markörler bitki çeşitlerinin tanımlanmas1, karakterizasyonu, genetik haritalama, marköre dayalı seleksiyon gibi çalışmalarda kullanılmışlardır (Yüksel vd., 2013; Ahsyee vd., 2014; Kafkas vd., 2015; Kalkışım vd., 2016; Çalışkan vd., 2017; Dervishi vd., 2018; Garcia-Gomez vd., 2019). Moleküler markörler içerisinde tekrarlanabilir olması, otomasyona uygun olması, genomda çok sıklıkla bulunması ve kodominant özelliği nedeniyle SSR tekniği önde gelen bir tekniktir (Zaloğlu vd., 2015; Güney vd., 2018, 2019).

Türkiye'nin bazı bölgelerinde yetişen ve çok fazla tanınmayan Yozgat iline bağlı Aydıncık ilçesinde yetiştiriciliği yapılan yerel Bağrıbütün kavunu da sahip olduğu eşsiz tat ve aroması ile piyasada söz sahibi olabilecek önemli bir genetik kaynaktır. Bu çalışmada, Yozgat Aydıncık Belediyesi tarafından coğrafi işaretlemesi yapılacak olan Aydıncık Bağrıbütün kavununun SSR tekniği ile DNA parmak izinin çıkarılması gerçekleştirilmiştir.

\section{Yöntem}

\subsection{Materyal}

Yozgat ili Aydıncık Belediyesi tarafindan tahsis edilen uygulama bahçesinde araştırmada kullanılacak Bağrıbütün kavunu tohumlarının ekimi yapılmıştır (Şekil 1). Deneme parselinde yetiştirilen Bağrıbütün kavunu bitkilerinden alınan yaprak örnekleri moleküler analizlerde kullanılmıştır.

\subsection{Metot}

\subsubsection{DNA İzolasyonu}

Doyle ve Doyle (1987)'nin geliştirdiği ve Kafkas vd., (2006) tarafindan modifiye edilen CTAB yöntemi kullanılarak DNA izolasyonu yapılmıştır. Bağrıbütün kavununa ait DNA'lar $-80^{\circ} \mathrm{C}^{\prime} \mathrm{de}, 300$ $\mu 1$ TE $(10 \mathrm{mM}$ Tris, $0.1 \mathrm{mM}$ EDTA, $\mathrm{pH}$ 7.4) içerisinde muhafaza edilmiştir.

\subsubsection{DNA Konsantrasyonunun Belirlenmesi}

DNA miktarları Qubit Fluorometre (Invitrogen) cihazı ve kiti kullanılarak belirlenmiştir. Daha sonra ise DNA'lar SSR analizleri için $10 \mathrm{ng} / \mu \mathrm{l}$ konsantrasyonuna ayarlanmıştır. 


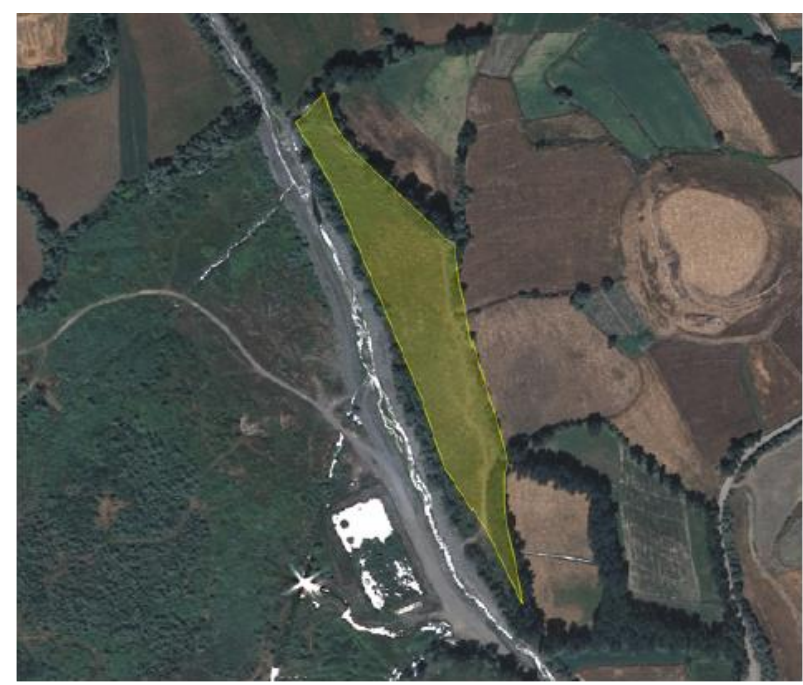

Şekil 1. Araştırmanın yürütüldüğü parselden bir görünüm (TC Tapu ve Kadastro Genel Müdürlüğü, Parsel Sorgulama uygulamas1 görüntüsü).

\subsubsection{SSR Primer Çiftlerinin Bağrıbütün Kavununda Allel Büyüklüklerinin Belirlenmesi}

SSR analizlerinde Ritschel vd., (2004), Gonzalo vd., (2005) ve Zhu vd., (2016) tarafindan geliştirilen 24 adet SSR primer çifti öncelikle polimorfizm bakımından taranmıştır (Tablo 1).

Tablo 1. SSR primer çiftleri ve sekansları

\begin{tabular}{|c|c|c|}
\hline No. & SSR Loci & Primer Sekans (5'-3') \\
\hline \multirow[t]{2}{*}{1} & CMSSR07989F & TGCGTGTCAAAATACGATGT \\
\hline & CMSSR07989R & TAATTGGGTGAGGTGCCTTC \\
\hline \multirow[t]{2}{*}{2} & CMSSR08902F & TTAATCTTGCGGTGGAAAGG \\
\hline & CMSSR08902R & TTAGGGAAGGCAATCAATCG \\
\hline \multirow[t]{2}{*}{3} & CMSSR16305F & TTTCTTGTGGTGGGTTGTTG \\
\hline & CMSSR16305R & ACСАТССАТТССААТTTССА \\
\hline \multirow[t]{2}{*}{4} & CMSSR09938F & GAAGGGGTTGAGGATAACGA \\
\hline & CMSSR09938R & TAATGGGTGGGAGGCAATAA \\
\hline \multirow[t]{2}{*}{5} & CMSSR06492F & TGCGTTGTTCCTAAATCAGACA \\
\hline & CMSSR06492R & TCTCTTATCCAACTCCTAAGCCA \\
\hline \multirow[t]{2}{*}{6} & CMSSR24136F & CGTGGGTTACTGACCAAAAA \\
\hline & CMSSR24136R & GGACCATTCTACCCTAGCCA \\
\hline \multirow[t]{2}{*}{7} & CMSSR04895F & GCGCAAATCAAGGGATTTTA \\
\hline & CMSSR04895R & ATGATTGGAAGCCACCAAAG \\
\hline \multirow[t]{2}{*}{8} & CMSSR10506F & GGTGAGGAATCCGATGAAGA \\
\hline & CMSSR10506R & TGAAGAACAAAGAGGGCTTGA \\
\hline \multirow[t]{2}{*}{9} & CMSSR12254F & ATGATTCCCGTAAGAATGCG \\
\hline & CMSSR12254R & ATTGAAGAGCGACCTGAAGC \\
\hline \multirow[t]{2}{*}{10} & CMSSR09316F & CCACGTGGTAGGAATTAATGTG \\
\hline & CMSSR09316R & CGTGAACTTTACTACGTAACGGC \\
\hline \multirow[t]{2}{*}{11} & CMSSR06905F & TCCATAAACATTTCCCCGTT \\
\hline & CMSSR06905R & GTGCAAATGCAAGATCGAAG \\
\hline
\end{tabular}

Tablo 1. devam1

\begin{tabular}{|c|c|c|}
\hline \multirow[t]{2}{*}{12} & CMSSR24606F & TGTGTGGTATTGAGGGCAAA \\
\hline & CMSSR24606R & ATGAGTGGCATTGGAGACAA \\
\hline \multirow[t]{2}{*}{13} & CMSSR04535F & AGGGGTTGGATTATTTTGGG \\
\hline & CMSSR04535R & TCTTTAAACCCCACGCAAAC \\
\hline \multirow[t]{2}{*}{14} & CMSSR03646F & ACCCGAAAAGAAGTGGGAGT \\
\hline & CMSSR03646R & AATGGACCСТTCTCСТCTCC \\
\hline \multirow[t]{2}{*}{15} & CMSSR27560F & AAACCGAAAACCAAGATGGA \\
\hline & CMSSR27560R & AATGGGGGTTTGTGTGAAAA \\
\hline \multirow[t]{2}{*}{16} & CMSSR23360F & ATGTCAATGCCTTGTGAAGC \\
\hline & CMSSR23360R & GAACAATGCAAGAAAATGGGA \\
\hline \multirow[t]{2}{*}{17} & CMSSR26616F & AGAGTCTCATTCCTCTCGACG \\
\hline & CMSSR26616R & TGTGTATGGAGGGCTTTTCC \\
\hline \multirow[t]{2}{*}{18} & CMSSR18058F & TACTCAАТTCСССАТСССТC \\
\hline & CMSSR18058R & TTTCCCAGCTTTTGTGGTTT \\
\hline \multirow[t]{2}{*}{19} & CMSSR05736F & CCTTCATCATTTCCAAGGGA \\
\hline & CMSSR05736R & GCCCTCCCAAAAATTTCAGT \\
\hline \multirow[t]{2}{*}{20} & CMSSR11104F & CAAAACTCCGATCAACACCA \\
\hline & CMSSR11104R & GTGGCAGAGTTCCGTTTTGT \\
\hline \multirow[t]{2}{*}{21} & CMBR107F & TATGAAGCGCGCATAAACAG \\
\hline & CMBR107R & GAATGTGAAATCTCTTCTCCC \\
\hline \multirow[t]{2}{*}{22} & $\mathrm{CMBR} 40 \mathrm{~F}$ & CGACAATCACGGGAGAGTTT \\
\hline & CMBR40R & TTGTTGCATCAAACTAACACAATC \\
\hline \multirow[t]{2}{*}{23} & CMCTN35F & CCAATAATGTAATCGTCTTGG \\
\hline & CMCTN35R & GTTCCAAАCTTTCTACCAATCA \\
\hline \multirow[t]{2}{*}{24} & CMCTN65F & TTAGGTGTATTTGATCTC \\
\hline & CMCTN65R & AATTTTATGGCTCAAGGTTC \\
\hline
\end{tabular}

SSR primerlerinin DNA'ya bağlanma sıcaklıkları $-58^{\circ} \mathrm{C}^{\prime}$ de, SSR-PCR döngü koşulları ise araştırıcıların kullandığı koşullarına göre yapılmıştır. Polimorfik olan 24 adet SSR primer çifti de Bağrıbütün kavun DNA'larının parmak izi analizinde kullanılmıştır.

Bağrıbütün kavun örnekleri için SSR-PCR işlemi tamamlandiktan sonra, PCR ürünlerinin elektroferezi ABI 3130xl otomatik baz dizileme ünitesinde yapılmıştır. SSR analizleri sonucu elde edilen bantların büyüklükleri birbirlerine çok yakın olduğu için \%1.5'lik agaroz jelde ayırmak mümkün olmadığından, elektroforez işlemi $A B I$ 3130xl kapiler elektroforez ile gerçekleştirilmiştir. SSR analizlerinin ABI 3130xl'de kapiler elektroforez yapılabilmesi için primerlerin 5, uçlarına M13 üniversal (5'TGTAAAACGACGGCCAGT-3`) baz dizisi eklenerek Schuelke (2000) ve SSR analizlerinde M13 primerinin 5' ucu 4 farkl1 (Applied Biosystems tarafindan tescilli 6-FAM, VIC, NED, PET) boya ile etiketlenerek kullanılmıştır. 
Analizler sonunda oluşan elektroferogram görüntüleri Genmap 4.0 (Applied Biosystems Inc.) paket programı kullanılarak Bağrıbütün kavununa ait DNA bantları pikler halinde değerlendirilerek primerlerin allelleri ve allel büyüklükleri belirlenmiştir.

\section{Bulgular ve Tartışma}

Yozgat'ın Aydıncık ilçesinde yetişen, kendine özgü hoş kokusu ve aroması olan coğrafi işaretlemesi yapılacak olan yerel Bağrıbütün kavununun DNA parmak izi bu çalışma ile ortaya çıkarılmıştır. Araştırmada deneme parselinden seçilmiş 4 adet genotipin 24 adet polimorfik SSR primeri ile genetik karakterizasyonu yapılmıştır. Bağrıbütün kavununun DNA parmak izinin çıarılmasında kullanılan CMSSR12254, CMSSR10506, CMSSR07989 ve CMSSR08902 primerleri yüksek oranda polimorfik olduğu için bu markörler Bağrıütün kavununun genetik karakterizasyonunda etkili bir şekilde kullanılabileceği belirlenmiştir (Şekil 2).

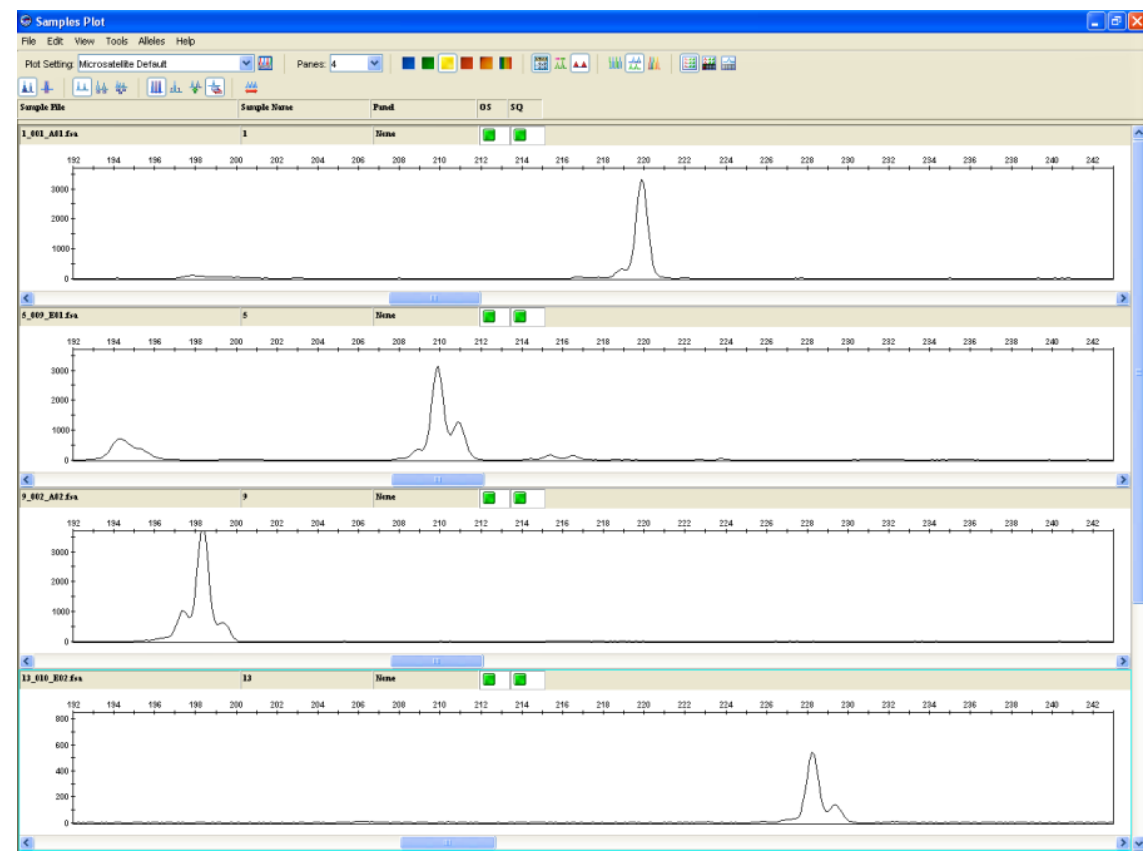

Şekil 2. Bağrıbütün kavununa ait elektroferogram görüntüsü

Moleküler markör teknikleri (ISSR, AFLP, SSR, vb.) kavun bitkisinde genetik ilişkilerin belirlenmesinde yaygın olarak kullanılmaktadır. Ege Tarımsal Araştırma Enstitüsü Ulusal Gen Bankasında yer alan toplamda 350 civarındaki kavun genotiplerinin faklı morfolojik özellik ve genetik karakterizasyon (SSR ve AFLP) analizlerinde elde edilen dendogram sonuçları benzerlik göstermiştir (Frary vd., 2009). İtalya'nın güneyindeki farklı coğrafik orijinli 13 inodorus kavunu 100 ISSR markörü ile genetik ilişkileri belirlenmiştir. Kavunlardaki genetik akrabalık analizleri ile morfolojik gözlem ve ölçümlerin arasında iyi bir korelasyon olduğunu saptamışlardır (Sestili vd., 2011). Hindistan'ın güneyinde 3 tarım bölgesinden toplanan 50 yerel çeşidin morfolojik özellikleri ve 17 SSR markörleri ile varyasyonunu değerlendirdirildiği diğer bir çalışmada ise genetik kaynaklar arasındaki çeşitlilik SSR analizleri ile ortaya çıkarmışlardır (Fergany vd., 2011). Türkiye'nin farklı bölgelerinde yetiştiriciliği yapılan yerel ve yabanc1 81 kavun genotipinin SSR markörleri ile aralarındaki akrabalık düzeyleri belirlemişlerdir. Soyağacında genotipler arasında genetik ilişkinin yüksek olduğunu saptamışlardır (Kaçar vd., 2012). Çin'de yapılan bir çalışmada ise, Xingjiang yerel kavun çeşitleri ile yabancı kavunlar arasında genetik bağlantıların düşük olduğu SSR markörleri ile saptamıştır (Ning vd., 2014). Sonuç olarak, literatürde yer alan çalışmalarda ve bu çalışmada, SSR markörleri ile yerel ve yabancı kavun genetik kaynakların varyasyonu, karakterizasyonu ve akrabalık düzeyinin belirlenmesi başaralı bir şekilde gerçekleşmektedir.

\section{Sonuçlar}

$\mathrm{Bu}$ araştırma da 24 adet polimorfik SSR primerinden 4 adedi ile Bağribütün kavunun DNA parmak izleri çıkarılmıştır. Bu SSR primleri ile 
kavun genetik kaynaklarının genetik ilişklileri daha kısa sürede ve daha güvenilir sonuçlarla belirlenebilecektir. Biyolojik çeşitliliğ̈in korunması ve biyolojik kaynakların sürdürülebilir bir biçimde kullanılması çabalarına katkıda bulunması açısından bu proje önem taşımaktadır. $\mathrm{Bu}$ proje ile Yozgat ekolojisinde yetişen, kendisine has aroması ve tadı olan, moleküler olarak tanımlanan, yerel Bağrıbütün kavunu genetik kaynak olarak da muhafaza altına alınmıştır. DNA parmak izlerinin belirlenmiş olması, genetik kaynağın yok olmasını önlenmenin yanı sıra ıslah çalışmalarına da yeni bir 1şık tutacaktır. Islah çalışmalarında ıslahçıların elinde ne kadar çok çeşitlilik bulunursa, yeni ve üstün özelliklere sahip çeşitlerin elde edilme başarısını o kadar artıracaktır.

\section{Teşekkür}

$\mathrm{Bu}$ çalışmayı destekleyen Yozgat Bozok Üniversitesi Bilimsel Araştırma Projeleri Birimi'ne (Proje No: 6604-ZF/18-183) ve Yozgat ili Aydıncık Belediyesi'ne teşekkür ederiz.

\section{Kaynaklar}

Ahsyee, R.S., Calic, I., Zoric, M., Karagic, D., ve Surlan-Momirovic, G., 2014. Enetic Diversity in Red Clover (Trifolium pratense L.) using SSR Markers. Genetika, 46(3), 949-961.

Çalışkan, M., 2005. Rapd Analizi ile Güllerde (Rosa spp.) Genetik Tanımlama. Ankara Üniversitesi, Fen Bilimleri Enstitüsü, Doktora Tezi, Ankara (in Turkish).

Çalışkan, O., Bayazit, S., Oktem, M., ve Ergul, A., 2017. Evaluation of the Genetic Diversity of Pomegranate Accessions from Turkey using New Microsatellite Markers. Turkish Journal of Agriculture and Forestry, 41(2), 142-153.

Dervishi, A., Jakse, J., Ismaili, H., Javornik, B., ve Stajner, N., 2018. Comparative Assessment of Genetic Diversity in Albanian Olive (Olea europaea L.) using SSRs from Anonymous and Transcribed Genomic Regions. Tree Genetics \& Genomes, 14(4), 53.

Doyle, J.J. ve Doyle, J.L., 1987. A Rapid Isolation Procedure for Small Quantities of Fresh Leaf Tissue. Phytochemical Bulletin, 19, 11-15.

Eser, B., Saygıll, H., Göçgol, A., ve İlker E., 2005. Tohum Bilimi ve Teknolojisi. Ege Üniversitesi Tohum Teknolojisi Uygulama ve Araştırma Merkezi İzmir, cilt 1 Yayın no:3 (in Turkish).

Fergany, M., Kaur, B., Monforte, A. J., Pitrat, M., Rys, C., Lecoq, H., Dhillon, N.P.S. ve Dhaliwal,
S.S., 2011. Variation in Melon (Cucumis melo L.) Landraces Adapted to the Humid Tropics of Southern India. Genetic Resources and Crop Evolution, 58(2), 225-243.

Frary, A., Doğanlar, S., Taşkın, T., Tan, A., İnal, A. ve Mutlu, S., 2009. Ulusal Kavun (Cucumis melo L.) Kolleksiyonlardaki Genetik Çeşitliliğin Belirlenmesi. TUBITAK, Proje No: 106O170, İzmir, 1-58 (in Turkish).

Garcia-Gomez, B., Gonzalez-Alvarez, H., MartinezMora, C., Cenis, L. J., Perez-Hernandez, C. D. M., Martinez-Zubiaur, Y., ve Martinez-Gomez, P., 2019. The Molecular Characterization of an Extended Mulberry Germplasm by SSR Markers. Genetika, 51(2), 389-403.

Gonzalo, M. J., Oliver, M., Garcia-Mas, J., Monfort, A., Dolcet-Sanjuan, R., Katzir, N., ... ve Monforte, A. J., 2005. Simple-Sequence Repeat Markers used in Merging Linkage Maps of Melon (Cucumis melo L.). Theoretical and Applied Genetics, 110(5), 802-811.

Gülşen, M. ve Mutlu, N., 2005. Bitki Biliminde Kullanılan Genetik Markırlar ve Kullanım Alanları. Alatarım, 4(2): 27-37 (in Turkish).

Günay, A. 1993. Özel Sebze Yetiştiriciliği. Cilt 5. A.Ü. Ziraat Fakültesi Bahçe Bitkileri Ankara 1993, (in Turkish).

Güney, M., Kafkas, S., Keles, H., Aras, S., ve Ercişli, S., 2018. Characterization of Hawthorn (Crataegus spp.) Genotypes by SSR Markers. Physiology and Molecular Biology of Plants, 24(6), 1221-1230.

Güney, M., Kafkas, S., Koç, A., Aras, S., Keles, H. ve Karc1, H., 2019. Characterization of Quince (Cydonia oblonga Mill.) Accessions by Simple Sequence Repeat Markers. Turkish Journal of Agriculture and Forestry, 43, 69-79.

İnal, A., 2002. Yerel Çeşitlerin Önemi ve Korunması. Broşür ETAET, No: 3 İzmir (in Turkish).

Kaçar, Y.A., Simsek, O., Solmaz, I., Sarı, N. ve Mendi, Y.Y., 2012. Genetic Diversity Among Melon Accessions (Cucumis melo L.) from Turkey based on SSR Markers. Genetics and Molecular Research, 11(4), 4622-4631.

Kafkas, S., Khodaeiaminjan, M., Gueney, M., ve Yasa Kafkas N.E., 2015. Identification of Sex-Linked SNP Markers using RAD Sequencing suggests ZW/ZZ Sex Determination in Pistacia vera $\mathrm{L}$. BMC Genomics, 16, 98.

Kafkas, S., Özgen, M., Doğan, Y., Özcan, B., Ercişli, S., ve Serçe, S., 2008. Molecular Characterization of Mulberry Accessions in Turkey by AFLP Markers. Journal of the 
American Society for Horticultural Science, 133, 593-597.

Kafkas, S., Özkan, H., Ak, B.E. Açar, I., Atlı, H.S. ve Koyuncu, S., 2006. Detecting DNA Polymorfism and Genetic Diversity in a Wide Pistachio Germplasm: Comparison of AFLP, ISSR and RAPD Markers. Journal of the American Society for Horticultural Science, 131(4), 522-529.

Kalkışım, O., Okcu, M., Okcu, Z., Karabulut, B., Yildirim, N., ve Agar, G., 2016. Relationships among Some Pears Genotypes (Pyrus communis L.) based on ISSR and RAPD Analysis. Erwerbs-Obstbau, 58(4), 259-264.

Kaşka, N., 2019. Meyveciliğin Gelişmesi Konusunda Çukurova'ya ve Türkiye'ye Yapılan Hizmetler. Çukurova Üniversitesi Rektörlüğü (in Turkish).

Kutlu, H., 2017. Konya İlinde Yerel Tohumların Kullanılması ve Sürdürülebilirliğine Etki Eden Faktörlerin Analizi. Doktora Tezi, Selçuk Üniversitesi Fen Bilimleri Enstitüsü. Konya 96s.

Ning, X. F., Xiong, L. M., Wang, X. L., Gao, X. W., Zhang, Z. G., Zhong, L. ve Li, G., 2014. Genetic Diversity among Chinese Hami Melon and Its Relationship with Melon Germplasm of Diverse Origins revealed by Microsatellite Markers. Biochemical Systematics and Ecology, 57, 432-438.

Özçağıran, R., Ünal, A., Özeker, E. ve İsfendiyaroğlu, M., 2004. Ilıman İklim Meyve Türleri. Yumuşak Çekirdekli Meyveler. Cilt: II. Ege Üniversitesi Ziraat Fakültesi Yayınları, No: 556, Bornova, İzmir (in Turkish).

Özgen, M., Adak, S., Söylemezoğlu, G., Ulukan, H., 2000. Bitki Genetik Kaynaklarının Korunma ve Kullanımında Yeni Yaklaşımlar. Türkiye Ziraat Mühendisliği 5. Teknik Kongresi, Ankara, s. 259-284 (in Turkish).

Pitrat, M., Halnelt, P., ve Hammer, K., 2000. Some Comments on Intraspesific Classification of Cultivars of Melon. Acta Horticulturae, 510: 29-36.
Ritschel, P.S., de Lima Lins, T.C., Tristan, R.L., Buso, G.S.C., Buso, J.A. ve Ferreira, M.E., 2004. Development of Microsatellite Markers from an Enriched Genomic Library for Genetic Analysis of Melon (Cucumis melo L.). BMC Plant Biology, 4(1), 9.

Schuelke, M., 2000. An Economic Method for the Fluorescent Labeling of PCR Fragments. Nature Biotechnology, 18(2), 233.

Sestili, S., Giardini, A. ve Ficcadenti, N., 2011. Genetic Diversity among Italian Melon Inodorus (Cucumis melo L.) Germplasm revealed by ISSR Analysis and Agronomic Traits. Plant Genetic Resources, 9(02), 214-217.

Şensoy, S., Büyükalaca, S. ve Abak, K. 2007. Evaluation of Genetic Diversity in Turkish Melons (Cucumis melo L.) based on Phenotypic Characters and RAPD Markers. Biomedical and Life Sciences, 54(6), 1351-1365.

Tan, A., 2009. Türkiye Geçit Bölgesi Genetik Çeşitliliğinin in situ (Çiftçi Şartlarında) Muhafaza Olanakları. Anadolu Ege Tarımsal Araştırma Enstitüsü Dergisi, 19(1), 1-13 (in Turkish).

Yüksel, C., Mutaf, F., Demirtaş, İ., Öztürk, G., Pektaş, M., ve Ergül, A., 2013. Characterization of Anatolian Traditional Quince Cultivars, based on Microsatellite Markers. Genetics and Molecular Research, 12(4), 5880-5888.

Zaloğlu, S., Kafkas, S., Dogan, Y., ve Güney, M., 2015. Development and Characterization of SSR Markers from Pistachio (Pistacia vera L.) and their Transferability to Eight Pistacia Species. Scientia Horticulturae, 189, 94-103.

Zhu, H., Song, P., Koo, D. H., Guo, L., Li, Y., Sun, S., ve Yang, L., 2016. Genome Wide Characterization of Simple Sequence Repeats in Watermelon Genome and Their Application in Comparative Mapping and Genetic Diversity Analysis. BMC Genomics, 17(1), 557. 